\title{
Life Cycle Cost Analysis of a Standalone PV System
}

\author{
Abdul Qayoom Jakhrani \\ Faculty of Engineering, Universiti Malaysia Sarawak, \\ Kota Samarahan, Sarawak, Malaysia \\ e-mail: aqunimas@hotmail.com \\ Andrew Ragai Henry Rigit \\ Faculty of Engineering, Universiti Malaysia Sarawak, \\ Kota Samarahan, Sarawak, Malaysia \\ e-mail: arigit@feng.unimas.my
}

\author{
Al-Khalid Othman \\ Faculty of Engineering, Universiti Malaysia Sarawak, \\ Kota Samarahan, Sarawak, Malaysia \\ e-mail: okhalid@feng.unimas.my \\ Saleem Raza Samo \\ Faculty of Engineering, Quaid-e-Awam University of \\ Engineering, Science and Technology, Nawabshah, \\ Sindh, Pakistan \\ e-mail: sfaizsamo@yahoo.com
}

\author{
Shakeel Ahmed Kamboh \\ Faculty of Computer Science and Information Technology, Universiti Malaysia Sarawak, \\ Kota Samarahan, Sarawak, Malaysia \\ e-mail: shakeel.maths@yahoo.com
}

\begin{abstract}
The purpose of this paper is to assess the viability of standalone photovoltaic (SAPV) systems for the supply of electricity in remote areas of Sarawak. In order to achieve the objectives, the life cycle cost (LCC) of a SAPV system was computed by means of net present value (NPV) technique. All anticipated costs were discounted to their present values by considering the time value of money. It was found that the capital cost makes up around $58 \%$ and future costs shares $42 \%$ of all expenses. PV modules contribute $9 \%$ and battery bank shares $52 \%$ with almost 8 days of autonomy at LLP of 0.01. Controller adds $5 \%$, inverter $8 \%$, civil work $17 \%$ and O\&M 9\% of total life time system cost. The estimated net energy cost from SAPV system was found to be US\$2.5/ $\mathrm{kWh}$, which is 20 times higher than average electricity tariff in Malaysia. It is concluded that the SAPV systems could only be preferred where the extension of power transmission lines is expensive for the supply of electricity in isolated areas.
\end{abstract}

Keywords- life cycle cost; discount rate; net present value; standalone photovoltaic system

\section{INTRODUCTION}

Economic analysis is an organized approach to find out the optimum solution of specific objective under the given assumptions and constraints [1]. In SAPV systems, the economic evaluations are being carried out to quantify the projected costs incurring from the system lifetime. Typically, two different types of costs are expected from solar PV systems, namely capital costs and future costs Capital costs are acquisition costs incur prior to the occupation of the facility including the installation cost and purchasing cost of system components [2]. Future costs are the forthcoming expenditures projected from the system operation [3]. Future costs are further classified into two parts, such as recurring and non-recurring costs. Recurring costs take place every year over the span of study period for example the operation, maintenance and repair costs. Operation and maintenance costs $\left(\mathrm{M}_{\mathrm{c}}\right)$ are planned costs to keep the PV system in good condition by deliberate inspections. Repair costs are unforeseen, and very difficult to predict when they will happen. For simplicity, the maintenance and repair costs are treated as recurring cost. For mature conventional systems, the annual $\mathrm{M}_{\mathrm{c}}$ is considered to be about $1 \%$ to $2 \%$ of the system's initial capital cost [4]. Non-recurring costs are known as onetime costs and they do not take place every year over the span of PV system life. These include replacement of major components. These costs are predictable expenditures that are required to maintain the smooth operation of facility.

\section{A. Economic Factors}

The major economic factors required for economic evaluations are life cycle length of system, inflation rate and discount rate. The length of the analysis period is chosen to be the best service life of the longest-living system component i.e. PV modules in case of SAPV systems. Inflation rate refers to a general rise in prices measured against a standard level of purchasing power. Typical annual inflation rates for remote power systems are 5 to $10 \%$ for fuel and 3 to $8 \%$ for non-fuel expenses [4]. The mean inflation rate in Malaysia was $2.77 \%$ reaching an historical high of $8.50 \%$ in July of 2008 and a record low of $-2.40 \%$ in July of 2009 from 2005 to 2010 [5]. Discount rate is defined as a rate of interest reflecting the investor's time value of money. The real discount rate in Malaysia from 1987-2010 was reported as $4.2 \%$ [5]. Discount rates have two types, real and nominal. Nominal discount rate includes the rate of inflation, whereas, the real discount rate excludes it. However, the use of either discount rate in its corresponding present value calculation derives same result [4]. The 